\title{
Special issue on digital transformation: challenges and opportunities
}

\author{
Wooje Cho ${ }^{1} \cdot$ Ming Fan $^{2} \cdot$ Byungjoon Yoo ${ }^{1} \cdot$ Han Zhang ${ }^{3}$ \\ Published online: 14 July 2021 \\ (C) The Author(s), under exclusive licence to Springer-Verlag GmbH Germany, part of Springer Nature 2021
}

This special issue of Information Systems and e-Business Management (ISeB) relates to the challenges and opportunities of digital transformation. Digital transformation refers to a firm's rethinking of how to use information technologies and other organizational resources to fundamentally change business performance and gain sustainable competitive advantages. A firm may be a digital predator or digital prey depending on the firm's strategy of digital transformation, according to Forrester Research (2015). Firms that take advantage of digital transformation opportunities are likely to dominate in the competition, while those ineffectively dealing with the challenges are likely to be digital prey. Digital transformation is occurring in every industry and is touching every company in a unique way. Today almost all the business activities, including strategy development, marketing activities, sales, operations, customer relationship management, and supplier relationship management, are in the scope of digital transformation.

Six research articles are included in this special issue; they present a broad overview of digital transformation. The first paper develops an economic model to investigate the impact of digitalization on the profitability of the vendor that sells digital goods. The second paper examines the relationship between dissatisfied customers and repurchase behavior in online markets. The third paper examines determinants of intention to purchase virtual items in mobile application games. The fourth paper analyzes survey data to identify factors that affect customers' intention to continually participate in online brand communities. The fifth paper discovers relationships between marketer-generated content (MGC), consumers' engagement with MGC, word-of-mouth, and purchase intentions, by analyzing data collected from the

Wooje Cho

woojecho@snu.ac.kr

1 Graduate School of Business, Seoul National University, 1 Gwanak-ro, Gwanak-gu, Seoul 08826, Korea

2 Foster School of Business, University of Washington, Box: 353226, Seattle, WA 98195-3226, USA

3 Scheller College of Business, Georgia Institute of Technology, 800 West Peachtree, NW, Atlanta, GA 30308, USA 
Weibo platform. The last paper studies the effect of review tag functions on product evaluation and information perception of products with experimental methods and qualitative analysis.

We especially thank Professor Michael J. Shaw, who is extremely supportive of this special issue. We also thank all the reviewers for their constructive suggestions and comments. Finally, we are deeply grateful to all the authors of the articles for their hard work and cooperation.

\section{Reference}

Fenwick N (2015) Digital predator or digital prey? Forrester Research, March 3

Publisher's Note Springer Nature remains neutral with regard to jurisdictional claims in published maps and institutional affiliations. 